\title{
NÜTZLICHE LÖSUNGEN
}

\section{Driver Assistance}

\section{Liebe Leserin, lieber Leser,}

während die einen über zu viele Lkw in verstopften Städten und über kilometerlange Elefantenrennen auf den Autobahnen lamentieren, aber gleichzeitig im Allgäu das Flensburger Bier trinken und in Hamburg den bayerischen Joghurt haben möchten, fahren die anderen mit ihren Brummies beständig Erfolge ein.

Die Wirtschaftszahlen zeigen die jetzigen Erfolge der Nutzfahrzeugbauer und Spediteure prägnant auf. „Die beiden vergangenen Jahre haben eine starke Erholung gebracht. In Westeuropa stieg der Absatz schwerer Nutzfahrzeuge (über sechs Tonnen) im Jahr 2011 auf rund 262.000 Einheiten“, sagte der VDA-Präsident Matthias Wissmann im Vorfeld zur 64. IAA Nutzfahrzeuge, die vom 20. bis 27. September 2012 in Hannover stattfinden wird. Das ist ein sagenhaftes Plus von 31 Prozent gegenüber 2009. Unter dem Motto „Nutzfahrzeuge: Motor der Zukunft“ wird in Hannover die Innovationskraft der Branche und die Effizienz des Nutzfahrzeugs unterstrichen. Ein Beispiel für heutige Technik ist der neue Mercedes-Benz Actros. Diese Zugmaschine wurde vom Antriebsstrang über den Rollwiderstand bis hin zur Aerodynamik optimiert. Dadurch verbraucht die Euro-VI-Variante des Actros nur noch rund 26 Liter Diesel auf 100 Kilometer - ganze 4,5 Prozent weniger als sein Vorgänger mit Euro V - und das trotz strengerer Abgaswerte.

Dieselabgase sind heute, „Elektro“ ist morgen. Wie der Stand der Technik in der Zukunft aussehen könnte, zeigt die RTWH Aachen im innovativen SmartWheels-Projekt ab Seite 652. Die beiden Institute ika und Isea haben einen ElektroKleinbus realisiert, der mit Ladepausen die Tageskilometerleistungen von Stadtbuslinien erreicht. Das ika hat dafür einen Versuchsträger aufgebaut; das Isea hat das Batteriesystem und eine innovative Schnellladevorrichtung entwickelt.
Trotz aller Euphorie bei technischer Entwicklung und wirtschaftlichen Zahlen: Auch das Nutzfahrzeuggeschäft spürt derzeit die Auswirkungen der Staatsschuldenkrise in den Ländern Europas. Der VDA erwartet für den westeuropäischen Markt im Gesamtjahr 2012 bei schweren Nutzfahrzeugen nur noch ein Neuzulassungsvolumen zwischen 256.000 und 250.000 Einheiten. Das entspräche einer Degression um zwei bis vier Prozent gegenüber dem Vorjahreswert. Über Europa hinausgeschaut, kommt es auch in Brasilien wegen der Einführung eines neuen Abgasstandards sowie konjunkturell bedingt zu einem Rückgang. China legt in diesem Jahr eine Wachstumspause ein und verzeichnet eine leichte Abnahme von drei Prozent.

Vorsichtiges Planen ist also geboten. Doch auf der IAA mit mehr Ausstellern und mehr Fläche als 2010 werden die Fachleute die passenden Antworten geben und nützliche Lösungen für den Transportmarkt von heute und morgen präsentieren.

Herzlichst, Ihr

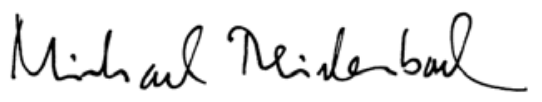

DIPL.-ING. MICHAEL REICHENBACH,

Stellvertretender Chefredakteur Wiesbaden 7. August 2012

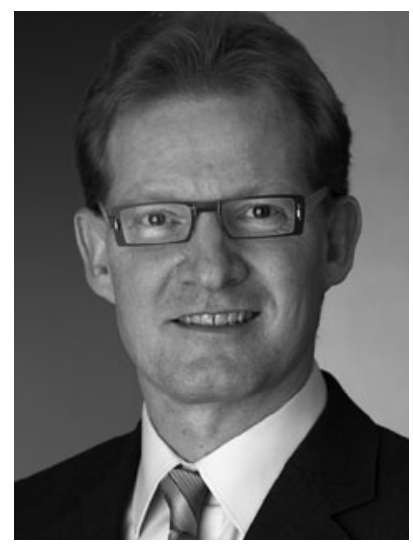

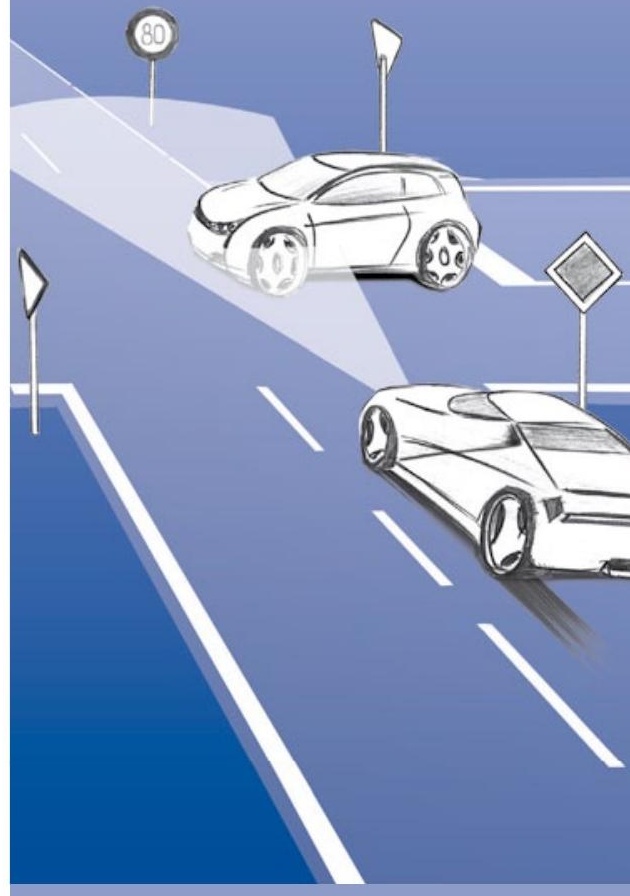

Entwicklung von

Fahrerassistenzsystemen
- Offene Simulationsumgebung mit Umgebungsverkehr, 3D-Straßenmodell, Sensormodell, Echtzeit-Animation u.v.m.

- Für sensor- oder kamerabasierte Systeme, Car2X Kommunikation und Energiemanagementfunktionen

- Virtuelle Testfahrten für Steuergerätetests in MiL-, SiL- und HiL-Umgebungen

\section{Top-Simulationsjobs}

Mehr erfahren und bewerben:

www.tesis-dynaware.com/jobs 